\title{
EFFECT OF COMPUTER BASED VISUALIZATION ON STUDENTS' COGNITIVE PROCESSES IN EDUCATION PROCESS
}

\author{
Renata Bilbokaite \\ Siauliai University, Lithuania
}

\begin{abstract}
Objectivized phenomenon in science education and their elements, revealed for students in the homogenized visual form, stimulate development of the Subject consciousness within the context of learning. Visualization is visual artefact represented in visual way aiming to code or decode information. By stressing this, the use of visualization during lessons of Biology, Physics, Geography and Mathematics becomes very important - it helps for perception, attention, memory and imagination that are needed during learning processes. This article encloses empirical data about effect of computer based visualization on students' cognitive processes. There were asked 2708 ninth and tenth form classes students in Lithuania. The results show that visualization is useful homogenously both for males and females, but females statistically significantly are sure about the positive effect of visual artifacts in the classroom.
\end{abstract}

Keywords: cognitive processes, science education, visualization.

\section{Introduction}

Visualization of the content of the science education is treated as the more simple representation of informationof the lesson is demonstrated by images within models constructed by the epistemic nature. Usually the content of learning is represented by verbal or symbolic codes, therefore the information, gained in such manner always aggravates the work of cognitive processes - the attention is not concentrated, the lower perception is observed as well as the worse remembering of the read or heard information. As it is indicated by researches (Lee et al., 2006; Khalil et al., 2005), flows of information, presented in schools are high, and within the educational context of transformation of paradigms they change rapidly, therefore it is more and more difficult for learners to select the essential material and to link it with the object of learning, epistemicaly related to the reality. Externalized visual representations compress information - information, presented in words, by aids of images can be minimally reduced, therefore it will be easier to perceive, memorize and remember. The time is saved, which, in opposite cases is wasted in reading verbal texts and trying to link them with the information, available in consciousness.

There is enormous number of scientist who stated that visualization has positive affect to human perception (Jared, 2009; Chittleborough, Treagust, 2008; Ubuz, 2007; Williamson, José, 2008; Saprykina, 2008; Kim, Olaciregui, 
2008; McCaffrey et al., 2008; Amundsen et al., 2008; Rogers, 2008; Tasker, Dalton, 2008; Ainsworth, 2008; Sengul, Cansu, 2010). Visual representations, presented during the learning, stimulate processes, responsible for the perception of information. Upon the domination of elements of verbal codes within the educational reality, the management of conceptions depends not only from the skill to memorise them exactly, but also from the depth of their assimilation, which is assessed after the successful implementation of practical tasks. The misperception of conceptions that appears due to the lack of experience and insufficient formal skills makes the thinking more difficult in later stages. As far as the verbal code is not perceived by learners, because it is sometimes too complex, its visual expression becomes more effective.

The visualization affects the memory of students (Cook, 2006; Card et al., 1999, cit. Folorunso, Ogunseye, 2008) implementation of regression within the consciousness due to factors of the progress through processes of perception is assessed as necessary for the perception of information only - for it to become clear. Visual materialisation of the content of the lesson strengthens the possibility to maintain the image in the memory for a long period of time and therefore to represent it in other form in any context or situation, e.g. in solving tasks or learning the new topic. Externalised visual representations, with the help of imagination (Rule, 2005), are internalised therefore processes of operation by images are implemented - rotations, spatial changes and development of the part of the world, which is subjectively perceived and objectively presented during the learning. Actualisation of imagination is linked with processes of visual thinking that are also activated, because, according to R. Arnheim (1998), the visual perception and imagination are its integral parts. Also, multidimensional visualization strengthens possibilities to activate the attention, because more sensual stimulus is included that effect centres of concentration (Kim, Olaciregui, 2008; Mason, 2006; Mammino, 2008; Tasker, Dalton, 2008).

The named psychological processes can be identified as cognitive, application of which affects the construction of more versatile mental models (Tasker, Dalton, 2008) in the memory, combining the verbal and visual schematic totality of codes, influencing the more effective assimilation of information of educational purpose as well as the formation of correct models in science education (Gilbert, 2008). It has been scientifically confirmed that application of visualization during lessons of Biology, Chemistry, Physics, Geography and Mathematics leads to the higher interest of students in educational content (Cook, 2006, Oller, 2006) and phenomenon of nature.

Theoretical factors are well known, but still, within changes of educational paradigm, attitude of students towards visualization and its effect is not clear because gradual introduction of technologies into educational process leads to the change in the understanding of the conception. New experience within transformation of culture is created, gradual transition to visual spaces is 
observed and therefore possible effect assessment of the visual object from the point of Subjects is not analysed but relevant and important. Even though various experiments identified that concrete externalised visualizations, applied in researches, are useful for cognitive processes of children, there is a lack of information about the possible effect of visualization, as the artefact, on the Subject - especially on very heterogenic aspect of gender. This would reveal psycho-educational specific features of application of visualization for girls and boys and could affect more cognitively and socially constructive creation of the educational process, because homogenous and heterogeneous peculiarities of the applied artefact during lessons of Biology, Chemistry, Physics, Geography and Mathematics would be known.

Object of the research - the effect of computer based visualization on students' perception, attention, memory and imagination in education processes.

Research aim is to enclose the effect of computer based visualization on students' cognitive processes in Biology, Chemistry, Physics, Geography and Mathematics.

\section{Methods of the survey}

Data collection methods: Questionnaire. Analysis methods for the survey data are two 1) descriptive statistics: Index of popularity, was applied to calculate ratings of variables; 2) analytical statistics: Mann'o Whitney U-test was applied for the comparison of variables from two independent samples; the test is applied on two independent samples with abnormal distributions of variables $(p<0.05)$. Hypothesis concerning the similarity of means of variables on the aspect of form and gender were verified by it.

\section{Research Methodology}

Description of Diagnostic survey and instrument. Diagnostics of the attitude of students was implemented with an aim to define the attitude of representatives of the population concerning psycho-educational aspects of applying visualization. On the base of results of the exploratory research, scientific literature and provisions of the researcher, the survey instrument was constructed and the diagnostic survey was implemented. All scales are interrelated and render psycho-pedagogical aspects of the survey object, obtained under evaluations of respondents and in this case, by the significant diagnostic data collection method. Scales of the questionnaire, sub-scales and statements have meanings and intervals (from 1 to 5, answer variant - from "always" to "never").

Internal reliability of the scale was measured by the Cronbach alpha coefficient - almost all sub-scales have rather high internal reliability Cronbach alpha is higher 0.7. According to this, it is possible to make a conclusion that questions of the questionnaire are appropriate to measure the object and are valid for some appropriate conclusions. 
Characteristics of the survey and sample. The random independent sample was formed under the serial principle. Three inquires were organized according to the object analysis in various disciplines. As far as subjects of Biology, Chemistry and Physics are interrelated on their content, it was treated that only one questionnaire is enough in order to analyze the attitude of students towards psycho-educational aspects of those subjects, identified as attributed to the science education. Geography and Mathematics, on their content are hardly interrelated. The low link with Biology, Chemistry and Physics is also observed; therefore in order to identify psycho-educational aspects of application of visualization within these disciplines, the additional number of students was to be interviewed for their attitude to be representative. 2708 students from 9-10 forms were interviewed, 728 from them expressed their attitude towards psychoeducational factors of applying visualization in Geography, 774 students expressed their attitude towards the same object in Mathematics and 1152 students - in science education subjects. The majority of respondents $-15-16$ years old students, dwelling in cities. More males if compared to females participated in the survey; however, with the high number of respondents it is believed that samples on aspects of gender and form are representative.

\section{Results}

The results of the research are presented in figures and explained in the below them.

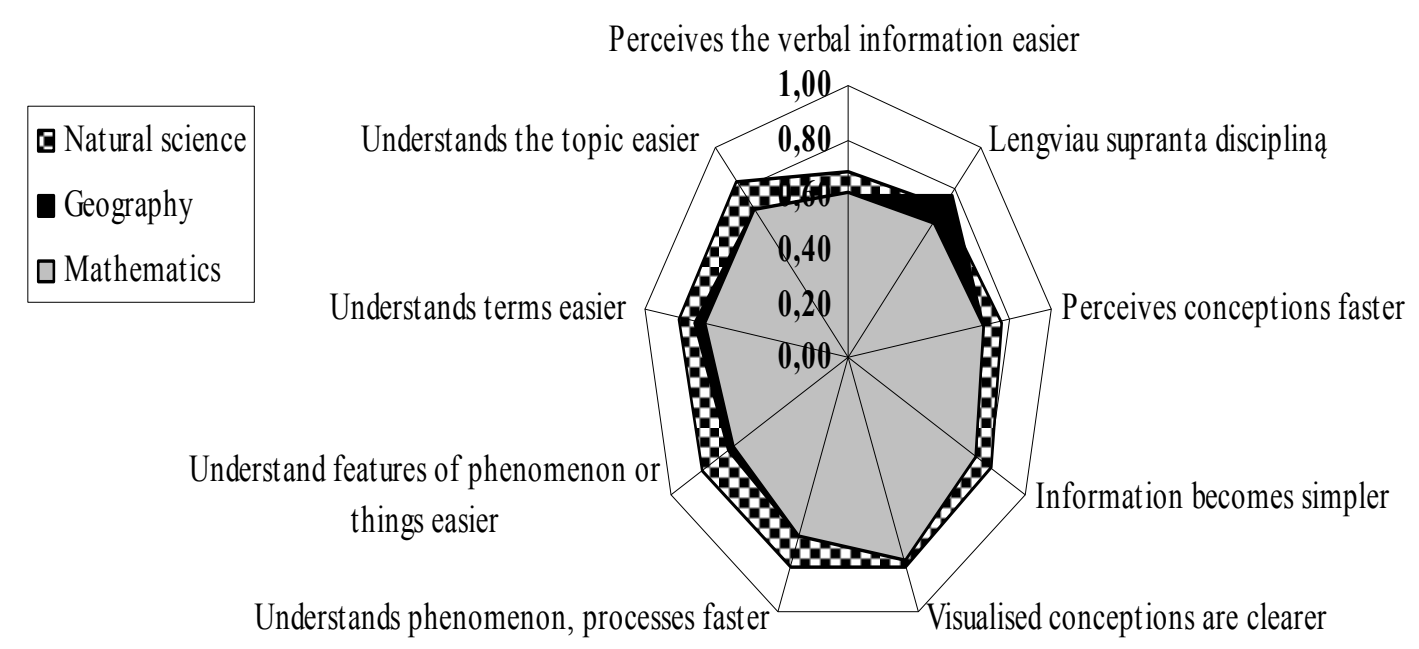

Figure 1. Effect of visualization on the visual perception upon learning / IP ( $=2708)$

The index of popularity means that the majority of variables was assessed by respondents as rather significant, because PI $>0.8$ and it indicates the approach to 1 in the scale of links, where the last number means $100 \%$ positive attitude of all respondents. Visualization, applied together with the verbal information, helps in many operations of perception. The highest position of rating is occupied by the effect of visualization on students from 9-10 forms in 
Lithuanian schools for the facilitation of the perception of the topic $(\mathrm{PI}=0.84)$. Images facilitates the perception of terms $(\mathrm{PI}=0.84)$ and phenomenon or features of things, makes the perception of phenomenon or processes from the process of science education faster (PI $=0.82$ ). Learning new topics becomes easier upon application of the visual expression of representation of objects, when it is matched with the verbal experience. According to respondents, the visualization also helps to perceive the information, because it becomes simpler $(\mathrm{PI}=0.81)$, implements the exploratory function of the complex verbal information. The last premise is confirmed by the high rating of the variable the depicted conceptions are clearer $(\mathrm{PI}=0.81)$.

The effect of visualization on perception was assessed similarly by respondents. Comparing the data on the aspect of gender it appeared that three statistically significant differences were found. Visualization statistically significantly for females $(\mathrm{p}<0.05)$ more than for males helps to perceive the verbal information, topics of science education disciplines and conceptions. Also, females statistically significantly more $(\mathrm{p}<0.05)$ than males perceive the topic, phenomenon and Geography if teachers of Geography during lessons apply the visualization. Females more than males $(p<0.05)$ think that the visualised conceptions during lessons of Mathematics are clearer for them.

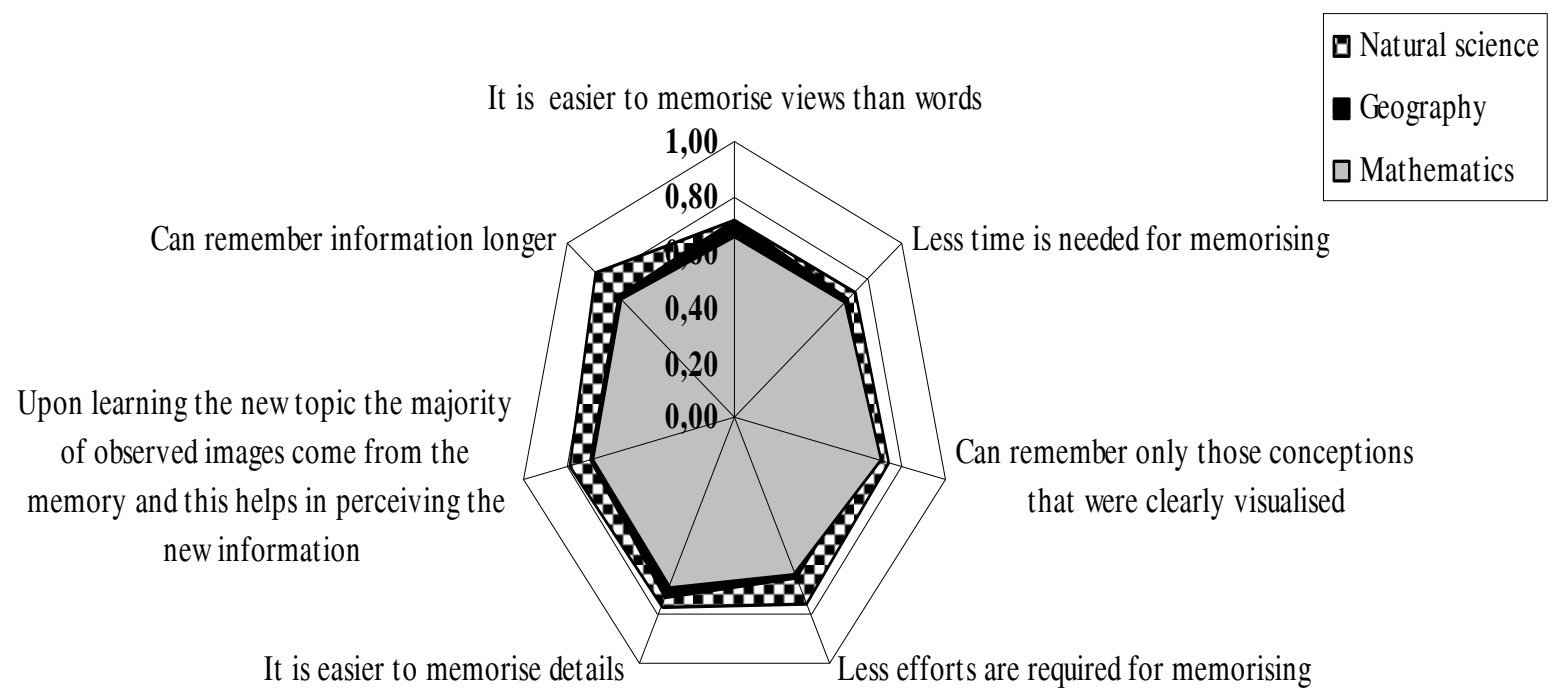

Figure 2. Effect of visualization on the visual memory upon learning / IP(N=2708)

The visual information, presented for the imaging of objects, can be useful for processes of memory: lower efforts are needed for memorising, the more correct mental models are formed that help in recognising similar objects, processes of selection become more rapid by selecting the memorised information as well as other processes. Figure XX presents ratings of statements, describing the help of the visualised information for processes of memory in science education. The highest index of popularity $(\mathrm{PI}=0.83)$ was given to the statement, stating that the visualization helps to memorise information and to 
maintain it in the long-term memory. It indicates that images, linked with the educational topic, help to memorise the information for a longer period of time; and the latter is very important, because they interlink with the majority of topics. The second position is occupied by the statement revealing operation of possible visual mental models during the process of learning, coded as upon learning new topics, the majority of observed images come from the memory and this helps in perceiving the new information ( $\mathrm{PI}=0.79)$. On the base of the latter it is believed that visual mental models are functioning in the consciousness that help to perceive and recognise similar codes, therefore the new information is matched to the available on and therefore the new cognition is formed.

The third position of ratings is occupied by the effect of visual information in memorising details $(\mathrm{PI}=0.75)$. The rating of the fourth statement indicates the assent of respondents that visualization can help them in learning because then lower efforts are required to remember information $(\mathrm{PI}=0.74)$. The majority of students remember complex phenomenon, objects and conceptions in science education only with the help of the visual information. It is likely that images, required for the perception and memorising of complex phenomenon implement functions of additional information. This premise is also likely to be liked with the style of visual learning, which is activated when the verbal information is too complex.

Females statistically significantly more $(p<0.05)$ than males remember conceptions that were visually depicted in science education. Also, females more than males $(p<0.05)$ believe upon learning of new topics the majority of images, observed during lessons of Geography come from the memory, therefore it is easier for them to perceive information. There was found another statistically significant difference - females more $(p<0.05)$ than males believe that they can remember information longer if it was presented not only verbally, but also by images in Mathematics.

Visual information is useful for the concentration of attention. The highest position is occupied by the statement linked with the better orientation in information ( $\mathrm{PI}=0.75)$ that reveals that the visual material helps to concentrate the attention to the totality and to learn more thoroughly. Dual data presentation is useful for students from ninth and tenth forms, because they can notice more details, rendered in the visual form. The lower positions are occupied by the effect of information on concentration (PI $=0.67)$, lower distraction $(\mathrm{PI}=0.66)$ and noise $(\mathrm{PI}=0.64)$. Those three statements have very similar index of popularity, therefore are similarly assessed by students, in this case, on the average level. The lowest rating is given to the statement that visualization help to follow information closer $(\mathrm{PI}=0.59)$.

Effect of visual information on the concentration of attention on the comparative aspect of gender has two statistically significant differences. It is to be stressed that for females as well as for males, the verbal text, presented with 
visualization, helps to concentrate the attention equally. It is easier for females than for males to get concentrated during lessons $(p<0.05)$, they are less distracted when the visualization is applied during lessons of science education.

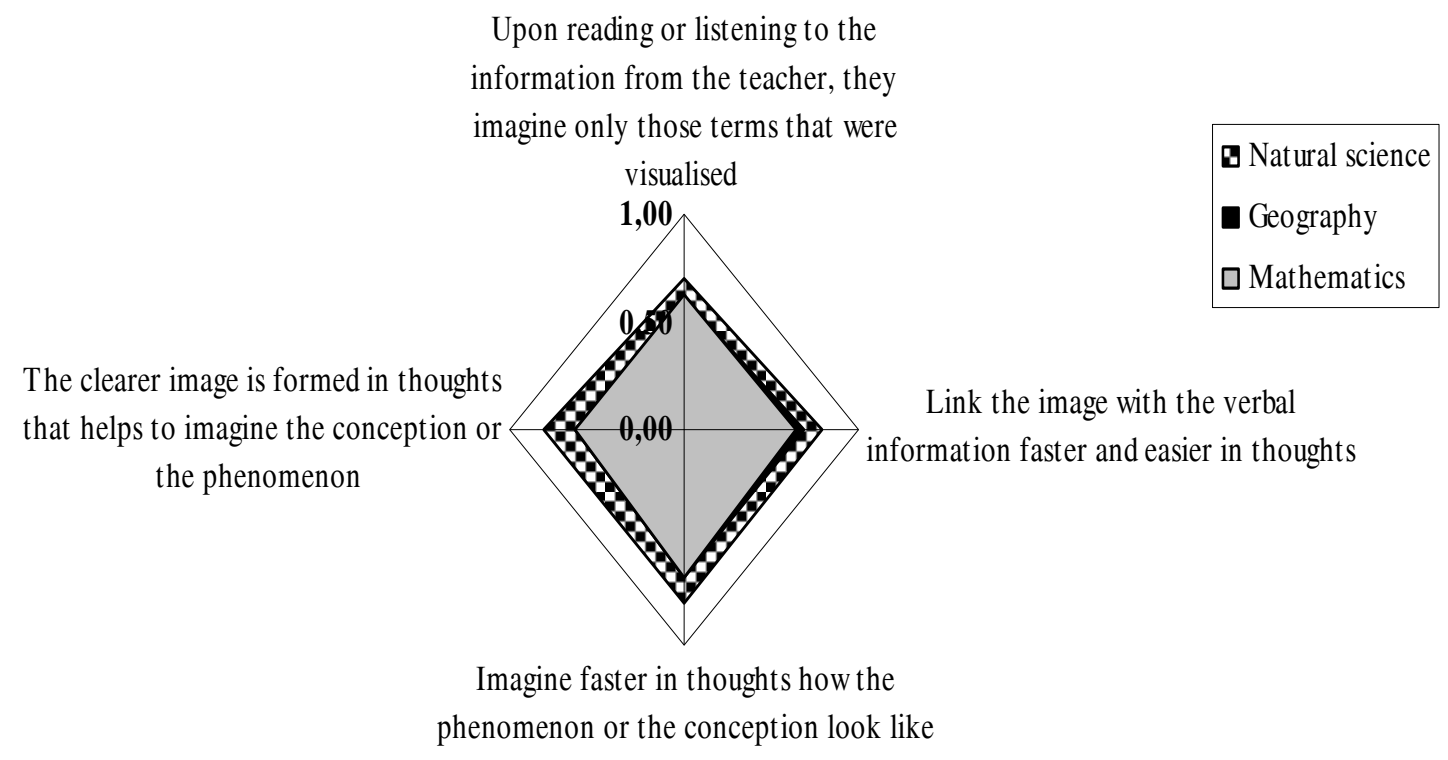

Figure 3. Effect of visualization on processes of imagination / IP ( $N=2708)$

Visualization, applied within the process of the science education, Mathematics and Geography can activate the processes of imagination of respondents. It appeared during the survey that two variables, revealing processes of imagination, have the similar rating, because their PI $>0.80$.

The comparative analysis reveals that there are two statistically significant differences, indicating the higher effect of applying the visualization together with the verbal information on imagination on the aspect of one gender. Visual representations are more useful for females $(p<0.05)$ because the clearer image is formed in their thoughts that helps to perceive the conception of the phenomenon, to imagine only visually observed terms when the teacher is talking about them or the student is reading by himself / herself. It is stated that visual representations for females help to form visual mental models on the base of which they use the decoded verbal conception and maintain the information longer in the memory. It is possible to state that visualization activates processes of imagination for females more than for males, important in learning disciplines of science education.

\section{Conclusions}

Students homogeneously identified the necessity of computer based visualization, as the artifact mediator in some particular subject, activity of cognitive processes is becoming more active: complex and abstract information is assimilated in a more easy and rapid manner, concentration is maintained for a longer period of time as well as concentration towards the educational content, 
unseen object, which have previously been represented by verbal codes and their interrelations, are imagined, the learnt material is kept in the long-term memory.

Computer based visualization is more useful for girls than for boys, because the clearer image is formed in their thoughts that helps to perceive the conception of the phenomenon, to imagine only visually observed terms, to get concentrated during lessons, to remember conceptions that were visually depicted and to hold it for longer time in memory, when the teacher is talking about them or the student is reading by himself / herself.

\section{References}

Ainsworth, S. (2008). The educational value of multiple-representations when learning complex scientific concepts. In J. K. Gilbert, M. Reiner, M. Nakhleh (Eds.). Visualization: Theory and practice in science education (pp. 191-208). Dordrecht: Springer.

Amundsen, Ch., Weston, C., McAlpine, L. (2008). Concept mapping to support university academics' analysis of course content. Studies in Higher Education, 33 (6), 633-652.

Chittleborough, G., Treagust, D. (2008). Correct Interpretation of Chemical Diagrams Requires Transforming from One Level of Representation to Another. Research in Science Education, 38 (4), 463-482.

Cook, M. P. (2006). Visual Representations in Science Education: The Influence of Prior Knowledge and Cognitive Load Theory on Instructional Design Principles. Science Education, Vol. 2 DOI:10.1002/acp.1344. Published Online in Wiley InterSience.

Folorunso, O., Ogunseye, O. S. (2008). Challenges in the Adoption of Visualization System: A Survey. Kybernetes, 37 (9-10), 1530-1541.

Gilbert, J. K. (2008). Visualization: An Emergent Field of Practice and Enquiry in Science Education. (pp. 3-25). Model and Modelling in Science Education. Visualization: Theory and Practice in Science Education. Ed. J. K. Gilbert, M. Reiner, Nakleh. Springer.

Khalil, M. K., Paas, F., Johnson, T. E., Payer, A. F. (2005). Interactive and Dynamic Visualizations in Teaching and Learning of Anatomy: A Cognitive Load perspective. The Anatomical Record, 286B (1), 8-14.

Kim, P., Olaciregui, C. (2008). The effects of a concept map-based information discplay in an electronic portfolio system on information processing and retention in a fifth-grade science class covering the Earth's atmosphere. British Journal of Educational Technology, 39 (4), 700-714.

Lee, Chun-Y., Yuan, Y. (2010). GenderDifferences in the Relationship between Taiwanese Adolescents' Mathematics Attitudes and Their Perceptions toward Virtual Manipulatives. International Journal of Science and Mathematics Education, 8, (5), 937-950.

Mammino, L. (2008). Teaching Chemistry with and Without External Representations in Professional Environments with Limited Resources. (pp. 155-186). Model and Modelling in Science Education. Visualization: Theory and Practice in Science Education. Ed. J. K. Gilbert, M. Reiner, Nakleh. Springer.

Mason, D. S. (2006). Small World, Common Ideas. Journal of Chemical Education,Vol. 83, (1), 9-29.

Jared, M. (2009). Visualizing Multi-Analytical Clinical Chemistry Data via Simple Patterns. Laboratory Medicine, 40 (1), 15-18. 
McCaffrey, K. J. W., Feely, M., Hennessy, R., Thompson, J. (2008). Visualization of folding in marble outcrops, Connemara, western Ireland: An application of virtual outcrop technology. Geosphere, 4 (3), 588-599.

Oller, A. R. (2006). Medium Velocity Spatter Creation by Mousetraps in a Forensic Science Laboratory. American Biology Teacher, 68 (3), 159-161.

Rogers, B., Denny, D., Stichbury, J. (2010). Towards TeachingSecondary SchoolPhysics in an Immersive 3D Game Environment. International Journal on Computing, 1 (1), 3035 .

Rule, A. C. (2005). The rhyming peg mnemonic device applied to learning the mohs scale of hardness. Journal of Geoscience Education, 51 (5), 465-473.

Saprykina, G. A. (2008). Electronic tutorials for school disciplines teaching and learning. Problems of Education in the 21st Century, 5, 145-153.

Sengul, S. A., Cansu, F. I. (2010). Pre-service Teachers' Perceptions and Preferences About Visualization. Procedia Social and Behavioral Sciences, 2, 2227-2232.

Ubuz, B. (2007). Interpreting a graph and constructing its derivative graph: stability and change in students; conceptions. International Journal of Mathematical Education in Science \& Technology, 38 (5), 609-637.

Tasker R., Dalton R. (2008). Visualizing the Molecular World - Design, Evaluation, and Use if Animation. Model and Modelling in Science Education. Visualization: Theory and Practice in Science Education. (103-132). Ed. J. K. Gilbert, M. Reiner, Nakleh. Springer.

Williamson, V. M., José, T. J. (2008). The effects of two-year molecular visualization ecperince on tearchers' attitudes, content, knowledge and spatial ability. Journal of Chemical Education, 85 (5), 718-723. 